\title{
Fetal Origin of Adult Disease
}

\author{
${ }^{1}$ Narendra Malhotra, ${ }^{2}$ Jaideep Malhotra, ${ }^{3}$ Neharika Malhotra Bora, ${ }^{4}$ Rishabh Bora, ${ }^{5}$ Keshav Malhotra
}

\section{ABSTRACT}

Fetal origins of adult disease, a concept first popularized by Dr David Barker, has subsequently led to many studies which have provided the evidence that certain diseases do have links pointing to fetal origins-adverse influences early in development, and particularly during intrauterine life, can result in permanent changes in physiology and metabolism, which result in increased disease risk in adulthood.

Links that are well-established are-reduced birth weight and increased risk of coronary heart disease, hypertension and stroke in adulthood.

The concept of a fetal origin of adult disease have been extended well-beyond coronary heart disease and being a risk factor for coronary heart disease, and now includes investigations of the development of the central nervous system, early origins of adult mental health and cognitive function.

By understanding fetal origin of adult disease, health care professionals and policy makers will make this issue a high health care priority and implement preventive measures and treatment for those at higher risk for chronic diseases.

Keywords: Adult disease, Barker's hypothesis, Epigenetics, Fetal programing.

How to cite this article: Malhotra N, Malhotra J, Bora NM, Bora R, Malhotra K. Fetal Origin of Adult Disease. Donald School J Ultrasound Obstet Gynecol 2014;8(2):164-177.

\section{Source of support: Nil}

Conflict of interest: None

\section{INTRODUCTION}

The quote and saying of Yesteryears: "child is the father of man' hold good today as it is seen that the nutritional status of fetus, infant and childhood is associated with a lot of adult hood diseases (diabetes, hypertension, cardiovascular

${ }^{1}$ Professor, ${ }^{2}$ Consultant, ${ }^{3}$ Lecturer, ${ }^{4}$ Resident (2nd Year), ${ }^{5}$ Intern

${ }^{1}$ Dubrovinick International University; President, FOGSI (2008); Consultant, Department of Obstetrics and Gynecology Managing Director, Rainbow Hospital, Agra, Uttar Pradesh, India

${ }^{2}$ President Elect, ASPIRE 2014; Department of Infertility and ART Specialist; Consultant, Department of Obstetrics and Gynecology; Director, Medical Services, Rainbow Hospital Agra, Uttar Pradesh, India

${ }^{3}$ Department of Obstetrics and Gynecology, Bharati Vidyapeeth Medical College, Pune, Maharashtra, India

${ }^{4}$ Department of Radiology, Bharati Vidyapeeth, Pune, Maharashtra India

${ }^{5}$ District Hospital, Agra, Uttar Pradesh, India

Corresponding Author: Narendra Malhotra, Consultant, Department of Obstetrics and Gynecology, 84 MG Road, Agra, Uttar Pradesh India, Phone: +91-9837033335, e-mail: mnmhagra3@gmail.com diseases, pre-eclampsia, IUGR, metabolic syndrome and many others).

About 24 years ago, David Barker, of Southampton University, in England, wondered if some adult diseases had their roots at the beginning of life, in developmental 'decisions' taken by fetuses (Fig. 1). Sometimes these decisions might be forced on a fetus by less than ideal circumstances. Sometimes they would be guesses about the future that turned out to be wrong. But the result in all cases would be misery in later life. ${ }^{3}$

Dr Barker's idea has spread. It is now the subject of investigation by researchers all over the world, many of whom had just spent four days in Brighton discussing it at the second conference on fetal origins of adult disease. Heart disease, obesity and late-onset diabetes frequently seem to trace their origins back to conditions in the womb, or in the first few weeks of infancy. So do cognitive ability, earning power, and even greed and sloth.

This is a new take on biological determinism. It is not an individual's genes that are predisposing his fate, but his uterine environment. Or, at least, it is some combination of the two. For, as is so often forgotten in all the arguments about nature and nurture, environments can be just as prescriptive as genes.

Diseases have genetic origins and epigenetic modulations (Fig. 2). Epigenetic factors like improper environment and nutrition are now proven to have a bearing on adulthood diseases and today a lot of interventions can be planned and done to make the environment favorable to a disease free fetus and infant and hence a healthy adult. ${ }^{4}$

Work of environmental modulations and nutritional interventions are being carried out by researches all over the world in a bid to find a prevention therapy for late onset adult-hood diseases. This indeed is a break through in science and simple interventions during pregnancy and during infancy and childhood may lead to a disease free adulthood. ${ }^{4}$

This may not hold true in all cases and hence cannot be put as a standard intervention and still needs scientific backing and proof.

The implications, notably for social and public-health policy, tend to reinforce the case for some measures that should be taken already. But there are surprises. Certain 'obvious' remedies turn out to be worse than no action. That reveals a dilemma. Is it better to act now with what common sense suggests is right - or to wait a decade or more for scientific confirmation (or disproof) of a possible policy? ${ }^{1}$ 


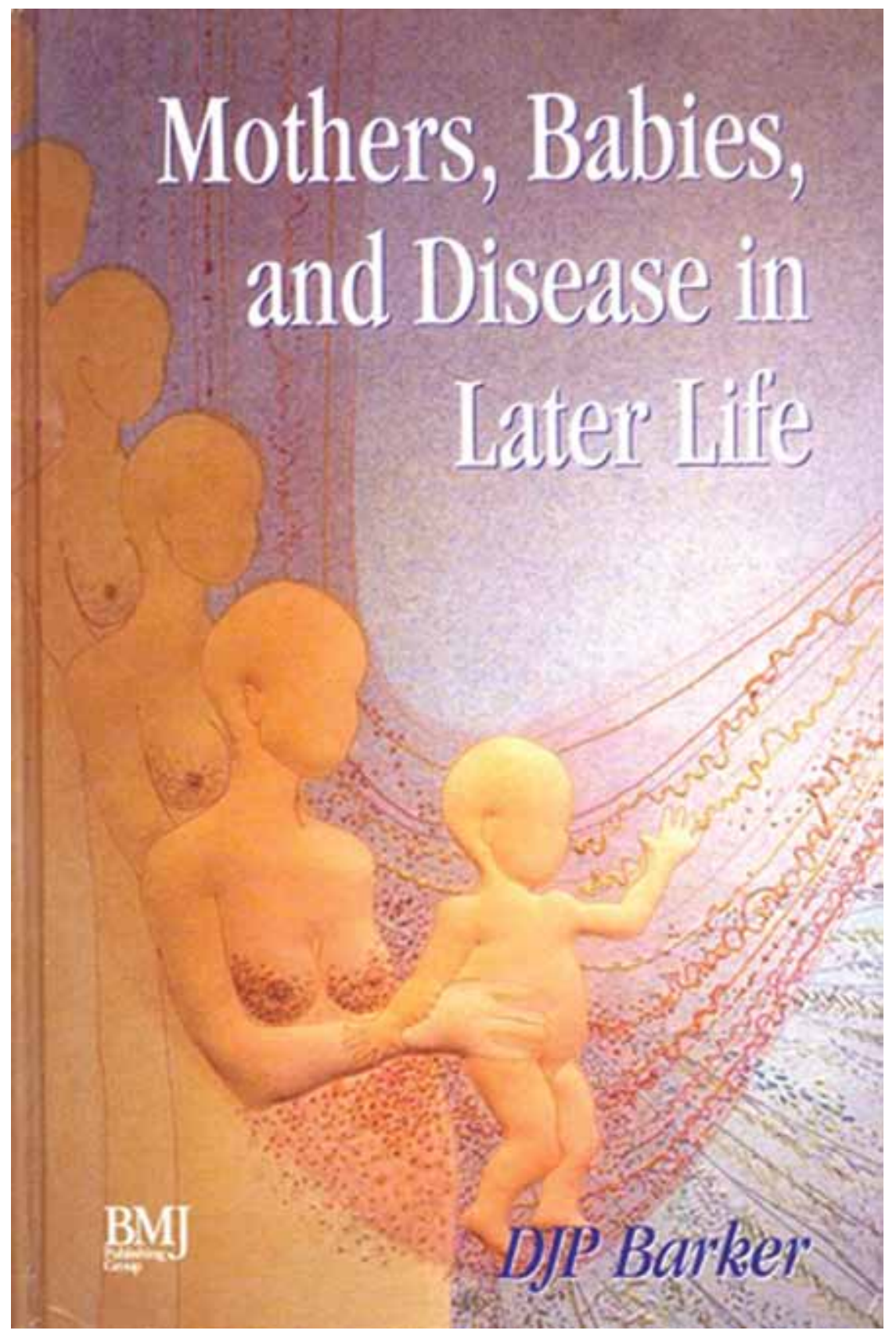

Fig. 1: David Barker concept published in BMJ, 1995

\section{HISTORY AND CURRENT STATUS OF BARER'S HYPOTHESIS ${ }^{2}$}

\section{Making the Best of Things}

Dr Barker's initial observation, based on several thousand people born in Hertfordshire before the second world war, was that babies who are particularly small grow into adults with a high risk of heart disease. Since then, low birth-weight has been associated with a collection of symptoms linked together in 1988 by Gerald Reaven of Stanford University, in California, and known as 'syndrome $X$ '. The features of this syndrome are high blood pressure, disturbed fat metabolism and obesity. These, in turn, are indicators of somebody who is likely to develop heart disease and late-onset diabetes (which also turned up in the Hertfordshire study). ${ }^{3}$

That small, food-deprived fetuses give rise to unhealthy adults is not exactly a surprise. What is surprising, though, is Dr Barker's idea that the pattern of their disease might be shaped by natural selection - in other words that it is programed into a developing fetus.

There are two prongs to this hypothesis (Fig. 3). The first is that a fetus has to cut its coat according to its cloth. Faced with a limited amount of food, it has choices about how to use it. Dr Barker's suggestion is that food will be allocated in ways that give an individual the best chance in early life, at the expense of later years when he will have had children 

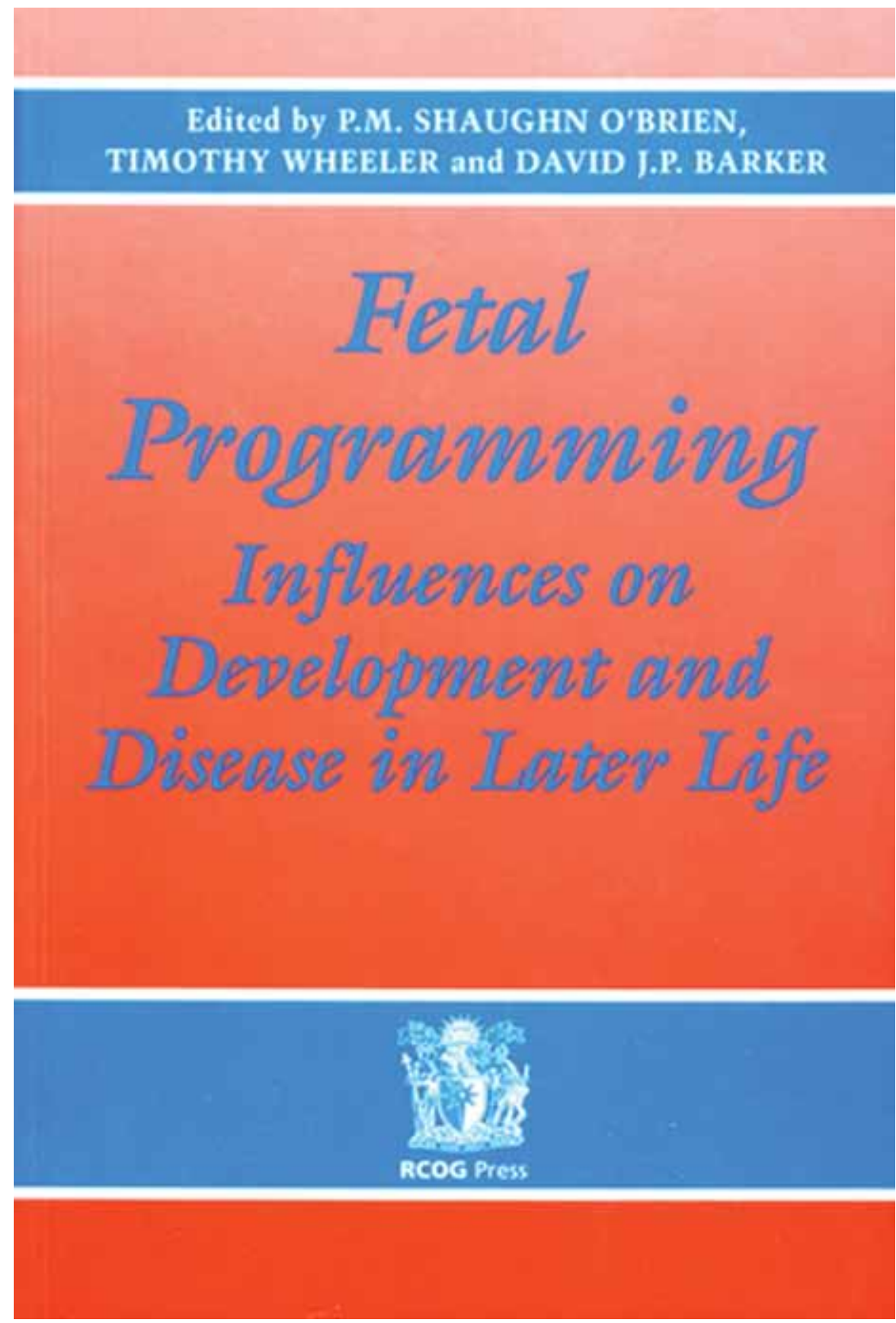

Fig. 2: RCOG publication on fetal programming in 1999

and might, indeed, have died of something else. Above all, the growth of the brain is protected.

The second prong is that a fetus takes its cue about what it will eat after it is weaned from its mother's physiology, and adapts accordingly. In this case, disease is caused when the prediction is wrong. In particular, individuals adapted for a low-calorie, low-fat environment who find themselves, through improved circumstances, in a high-calorie, high-fat environment, might be expected to have problems.

There is evidence for both prongs. The idea that the brain is protected is supported by work carried out on rats by Susan Ozanne at Cambridge University. Dr Ozanne and her colleagues fed a group of pregnant rats a normal diet, and another group a restricted diet. They then measured the sizes of the brains, pancreases and muscles of the pups that were born. The pancreases and muscles of the pups born to restricted-diet mothers were much smaller than those of pups born to mothers on normal diets. Their brains were smaller, too-but only a little. And compared with body size, those brains were actually proportionately larger than those of pups born to well-fed mothers.

This appears to happen in people, as well. Towards the end of the second world war, the Netherlands was gripped by a famine known as the Dutch hunger winter. Men who were born just after this famine had abnormally large heads compared with their body weights. 


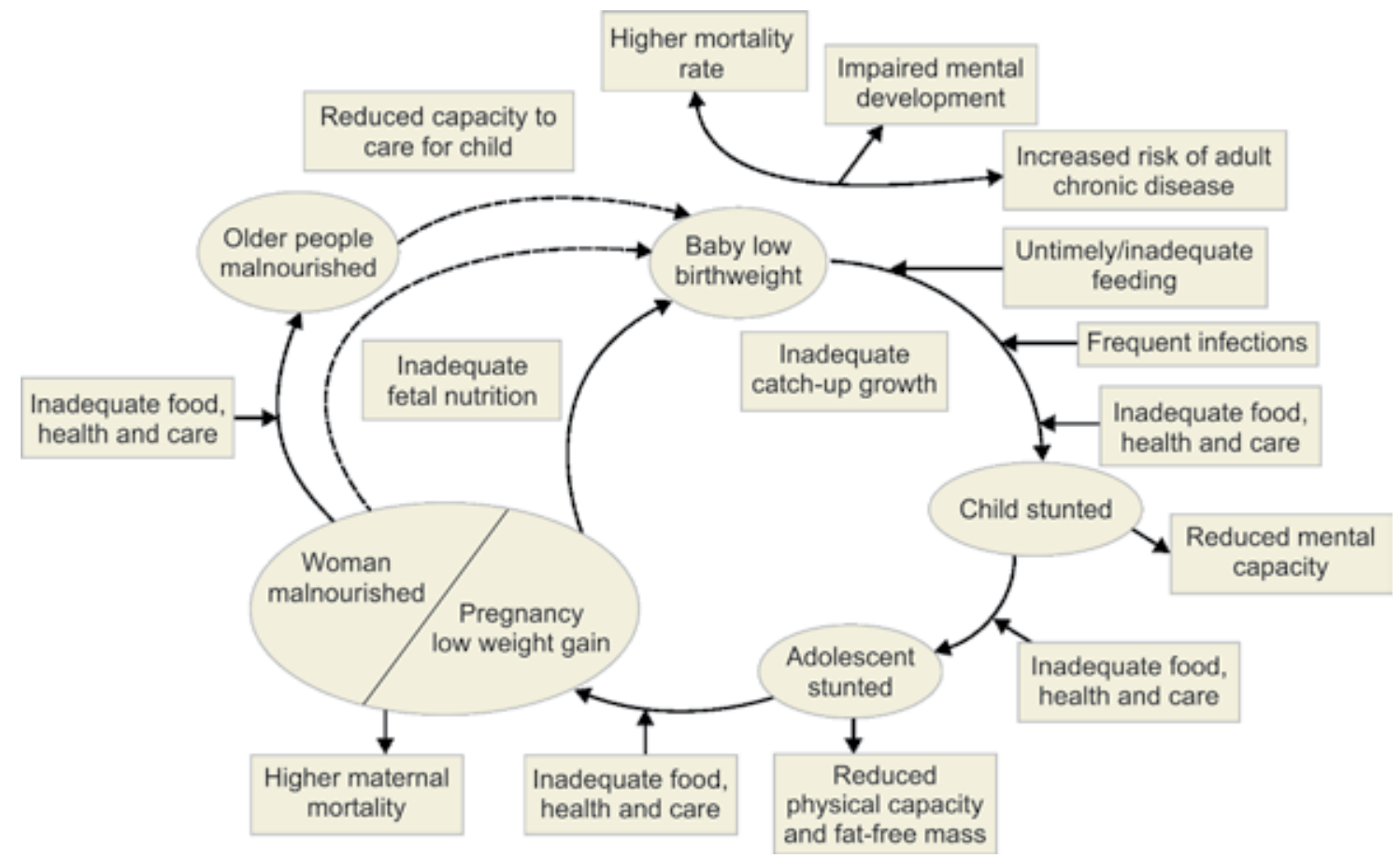

Fig. 3: Maternal nutrition and lifestyle to fetal growth

There is also evidence that developmental compromises made by a fetus are, indeed, designed to put off the evil day when their consequences must be faced. For example, the high blood pressure associated with syndrome X stems, at least in part, from the way the kidneys develop. According to Barry Brenner, of Brigham and Women's Hospital, in Boston, Massachusetts, the kidneys of growth-restricted fetuses have fewer nephrons (the urine-forming elements) than those of normal fetuses. This saves resources, but means that each nephron has to work harder, which in turn means that they wear out and die faster. The result is yet fewer nephrons, so that each has to work harder still. And so on. Nephrons control blood pressure, so the result is hypertension. But it does not happen immediately. A study of conscripts in Sweden showed that at the age of 20 years, birth-weight has no effect on blood pressure. But after the age of 50, the effect appears and then grows ever larger.

Both these results suggest that fetuses do, indeed, cut their coat according to their cloth. And there is also evidence that they try to anticipate bad times-often with disastrous consequences.

Dr Barker's idea is that a fetus faced with a lack of nutrients develops thrifty habits. Developmental pathways are controlled by genes, but those genes are subject to regulation. Exactly what changes in genetic regulation are involved in the programing of thrift are unclear, although a few of the genes involved have been identified. However, the result, according to Dr Barker, is twofold. First, the fetus's tissues become more resistant to insulin - a molecule that opens the door for glucose to enter cells, so that it can be burned to release energy, or used as a feed-stock to make other molecules. Second, the fetus becomes better able to lay down fat deposits in later life.

The insulin resistance, according to this idea, diverts glucose to the brain by keeping it available in the bloodstream. Insulin resistance stops muscles and other organs taking glucose up, but the brain (uniquely) does not need insulin to help it to absorb this sugar. Once programed in, though, insulin resistance cannot be programed out again. Too much insulin resistance causes blood-sugar levels to rise dangerously. In other words, it causes diabetes (This is a different form of the disease from the one caused by lack of insulin). ${ }^{5}$

The advantage of laying down fat when food is plentiful is more obvious. It helps mature animals to get through lean times. Peter Gluckman, University of Auckland, in New Zealand, even goes so far as to describe the human 'beer' belly as the equivalent of a camel's hump. These days, however, there are no lean times. Diets are calorie-rich, and getting more so. As a result, both mechanisms are going horribly wrong. Even in the west, people conceived a decade or two ago are eating far more sugar and fat than their mothers did. The shift is greater still in many poor and middle-income countries. The result is epidemics of obesity, diabetes (due to too much blood sugar) and heart disease (due to high blood pressure and disturbed fat metabolism associated with changes in the body's fat-storing cells).

Mark Vickers, also from Auckland (a university that clearly knows the value of a good turn of phrase), has a catchier name than syndrome $\mathrm{X}$ for the phenomenon. He 


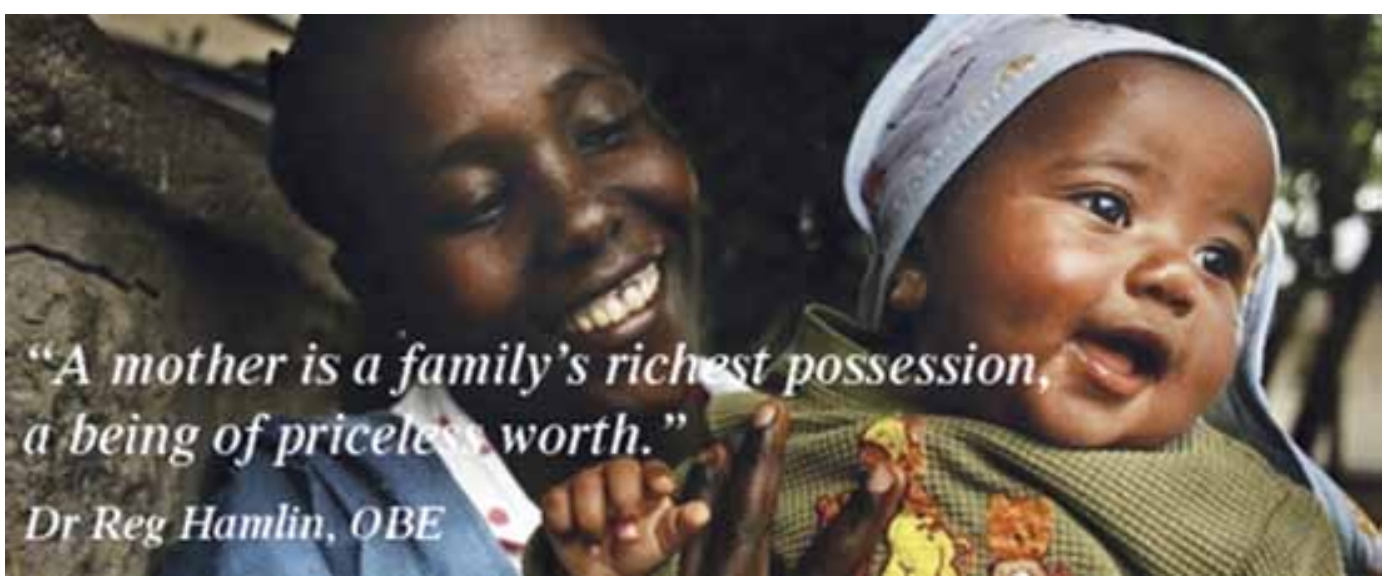

Fig. 4: Quote by Dr Reg Hamlin

calls it couch-potato syndrome. That is because he has identified two other symptoms: greed and sloth. In rats, Dr Vickers's favored experimental animals, low birth-weight pups from food-deprived mothers both eat more and are less active than those of normal weight from well-fed dams. There is every reason to believe that the same holds true for people.

This makes good sense. If the uterine environment suggests food is scarce, developing behavior that both consumes as much as possible and conserves energy is wise. But combine it with a remote control, a bucket of fried chicken and a six-pack of beer, and the result will be that you put on not a hump, but a mountain (Fig. 4).

\section{No Head Start}

Although Dr Ozanne's work suggests that the developing fetus does its best to protect its brain, that is not always enough. Johan Eriksson, of the National Public Health Institute in Helsinki, studied a group of Finnish men born in 1940. Their size as infants (admittedly measured when they were a year old, rather than at birth) was a disturbingly good predictor of their incomes 50 years later. Those $72 \mathrm{~cm}$ long at that age had an average income of $\$ 27,000$. Those $78 \mathrm{~cm}$ long had an income of $\$ 39,000$. The assumption-backed up by the men's school records when they were boys - is that this disparity is caused by differences in cognitive ability which are, in turn, the result of variations in early growth.

Body size is a relatively crude measure. Alan Lucas, of University College, London, reported a result that was even more disturbing. Like Dr Eriksson's work, Dr Lucas's study was not of children still in the womb. But, in a sense, they should have been, for they were all born prematurely. Dr Lucas looked at the effects of feeding such premature babies with a nutritionally enhanced 'baby formula'. He compared their development with that of similar babies fed standard formula. The experiment lasted for a month immediately after birth. Then all the children went on to standard formula.
The children, 1,000 of them, were born almost two decades ago, so they have now grown up. They were tested at the age of seven, and again in their mid-teens. The boys who had had only standard-formula milk had noticeably lower IQs than the others. They were particularly bad at mathematics. At the time of the second test, several of them were also put in a brain scanner. A small area of their left parietal lobes was less active than expected. The left parietal lobe is known to be involved in doing mathematical calculations. This result suggests an obvious intervention: do not feed premature babies on standard-formula milk. Perhaps other dietary interventions might help, too.

\section{Eat-up Your Greens}

At first sight, the results look encouraging. Penelope Nestel of the Micronutrient Global Leadership Project, in Washington, DC, showed that giving expectant mothers in poor countries a balanced dietary supplement of protein, carbohydrate and fat helped to boost the birth-weights of their babies. Caroline Fall, one of Dr Barker's colleagues at Southampton, got similar results in India by encouraging expectant women to eat green vegetables in order to obtain micronutrients such as vitamins and minerals. But one has to be careful. Dr Nestel showed that diets which supplemented only proteins actually stunted fetal growth. Nor did pure micronutrient supplements have any effect on birth weight when she gave them to pregnant women. Policies based on these 'obvious' interventions would be, respectively, damaging and uselessly expensive.

For those already born, however, the secret is to overcome couch-potato syndrome-eat less and exercise more. Exercise, in particular, is important, according to Christopher Byrne, who also works at Southampton. Even if you do not lose weight, it oxidises fats. That improves sensitivity to insulin. And that reduces the risk of diabetes. Dr Byrne can watch the biochemical changes happening at the level of 
the messenger molecules that carry instructions from genes to the rest of the cell. Or you can watch it yourself in your increased chance of enjoying a healthy old age, regardless of your weight when you came out of your mother's womb.

\section{FETAL ORIGINS HYPOTHESIS}

\section{Role of Nutrition}

Neonatal size is strongly related to maternal BMI, height, head circumference and even birth weight. This probably has both genetic and environmental components, but strongly suggests that the nutrition of a female throughout her life (during her own fetal life and childhood) as well as during pregnancy, influences the growth of her fetus. ${ }^{6}$ Nutritional effects on fetal growth are also shown by the drop in birth weight observed during famines. ${ }^{7}$ There is some evidence that improvement in the micronutrient quality of mothers' diets leads to an increase in fetal growth. Among men and women born during the Dutch famine of 1944-45, late gestation exposure to famine was associated with glucose intolerance, insulin resistance, and a (small) increase in type 2 diabetes. Early gestation exposure was associated with higher LDL/HDL cholesterol concentrations and (in women) higher BMI and waist circumference. Three recent studies suggested that the balance of maternal protein and carbohydrate intakes during pregnancy is related to blood pressure in the offspring. ${ }^{8}$

\section{Low Birth Weight and Adult Cardiovascular Disease (CVD)}

Following up this theory, by using 1911 to 1930 birth records for one English county (Hertfordshire), Barker showed that lower birth-weight and weight at one year were associated with an increased risk of death from CHD and stroke. ${ }^{9,10}$ There was an approximate doubling of CVD mortality from the highest to the lowest extremes of birth-weight, similar in men and women. It is restricted fetal growth rather than pre-term delivery which carries the risk of CVD. The effects are linear, graded across the whole range of birth weight and independent of adult socioeconomic status.

\section{Cardiovascular Disease Risk Factors}

Subsequent work has shown that lower birth-weight and other measures of small size at birth are also associated with higher levels of some 'classical' CVD risk factors. Insulin resistance syndrome, blood pressure, type 2 diabetes, insulin resistance, and combination of these are consistently related to low birth-weight in a large number of studies in different populations. ${ }^{11,12}$

\section{Lipids and Clotting Factors}

Although lipids show some associations with size at birth, these are weaker and less consistent.

\section{Cardiovascular Function}

Arterial intima media thickness and carotid stenosis, examined using ultrasound, are increased in lower birth weight men and women and flow-mediated dilatation, a measure of endothelial function, is reduced in young adults and children of lower birth-weight. ${ }^{13-15}$

\section{Obesity}

People who were heavier at birth tend to become 'fatter' adults as measured by body mass index. However, this may reflect increased lean mass rather than adiposity. There is no evidence that low birth-weight leads to increased total body fat, but leptin concentrations were increased in low birthweight men and women in one study and central obesity has been linked to small size at birth. The sub scapular/triceps ratio is consistently higher in adults and children of lower birth-weight. ${ }^{16,17}$

\section{Postnatal Growth and Adult Obesity}

Cardiovascular disease and its risk factors are also linked to patterns of growth in infancy and childhood. In Hertfordshire, men with lower weight at the age of one year had increased CVD mortality and type 2 diabetes and also had higher fibrinogen and cholesterol concentration. This was confirmed in men born in Finland. ${ }^{18-20}$ Unlike weight gain during infancy, accelerated childhood weight gain is associated with an increased risk of high blood pressure in young adults.

\section{Fetal Growth and Type 2 Diabetes}

Low birth-weight is also associated with a high prevalence of the insulin resistance syndrome. Data from animals and recent human observations have suggested a mechanism in that adverse events in early life which lower birth-weight, appears to permanently alter or 'program' the secretion of stress hormones including cortisol. Together with obesity this leads to a high-risk of the metabolic syndrome and the predisposition to cardiovascular disease.

\section{Maternal Diabetes and Fetal Macrosomia}

Recent data shows that diabetes in mothers, which results in fetal macrosomia, also has an increased risk of obesity and type 2 diabetes in their offsprings compared with offspring of nondiabetic mothers or women who become diabetic after pregnancy. The difference in risk holds true for siblings born 
before and after the onset of maternal diabetes and is not seen among offsprings of diabetic fathers. Gestational diabetes produces a U-shaped or J-shaped relationship between birthweight and adult type 2 diabetes. ${ }^{19}$

\section{Neurodegenerative Disease}

There is preliminary evidence that a bacterial stimulus (endotoxin) can produce cytokines that impair the development of the mesencephalic dopaminergic systems during pregnancy leading to a possible increased risk for Parkinson's disease in later life. There is preliminary evidence that exposure to environmental neurotoxins during dopaminergic development enhances the susceptibility to accelerated dopaminergic cell death during aging. In utero exposure to polycyclic biophenols (PCGs) leads to altered thyroid function and subsequent learning disabilities later in life. ${ }^{21}$

\section{Immune System Programing}

The development of immune system, including the development of the repertoire of reactive lymphocytes that will exist in postnatal life, begins prenatally. Alteration of the fetal immune environment might preprogram the highly sensitive fetal immune system for aberrant immune regulation, leading to loss of tolerance to self- antigens and resulting in an increased risk for autoimmune disease. These changes might manifest in adult life and perhaps only after a second exposure to related environmental chemicals. There is evidence in humans and experimental animals that prenatal exposure to immunosuppressive drugs can lead to a higher risk of autoimmune disease in the later life. ${ }^{21}$

\section{Birth Defects and Fetal-basis of Adults Disease}

It is recognized that two to five percent of all live-born infants have a major birth defect. Approximately 40 percent of these defects are thought to be due to the effect (s) of an adverse exposure of genetically predisposed fetus to intrauterine environmental factors. Exposure to environmental agents during early development can result in death, structural malformation, and/or functional alteration of the embryo/ fetus. These toxicant induced pathogenic responses are most likely the result of altered gene expression associated with altered cell production and cell differentiation. ${ }^{21}$

\section{Cleft Palate}

Cleft lip and palate is common disfiguring birth defect and results from miscues during fetal development of facial structures. This may be triggered in the fetus by the mother's exposure to the environmental toxins and interactions. ${ }^{22}$

\section{Cardiac Malformations}

Cardiovascular malformations (CVM's) are the most common type of birth defect in the US, affecting almost $1 \%$ of live births. Causes include genetic, maternal disease, drugs such as phenytoin and cocaine, dietary factors such as folic acid deficiency, vitamin A excess and copper deficiency and certain environmental chemicals (e.g., paints, solvents and degreasers, pesticides, air pollutants, trichlorethylene, bisdiamine, dioxin). ${ }^{22}$

\section{Cancer}

Childhood leukemia and brain cancer may have environmental components in their development due to pesticides. DES daughters have risk of cancers and abnormalities in reproductive tract.

\section{Diabetes}

Type 1 diabetes mellitus is a common and serious disease of the childhood. There is 40 to $45 \%$ risk of inheriting this disease through high-risk HLA alleles and is influenced by other factors like viruses, nutrition, toxic agents and socioeconomic factors. Agricultural Health study from UK shows that the incidence is common in the areas with high nitrate levels in water.

\section{Controversies for the FOAD Hypothesis: Clinical Importance}

It has been argued that the increased risk of adult disease attributable to intra-uterine under nutrition is very small and the effects are most marked at the extremes of birthweight. In addition, effects of size at birth are conditioned by childhood growth and adult obesity and predict large differences in the risk of CHD, hypertension and diabetes. ${ }^{23}$

\section{Controversies for the FOAD Hypothesis: Genes vs Environment}

The time trends in CVD and type 2 diabetes in western countries and in different socioeconomic groups during the 20th century, and the recent rise in developing countries, suggest a susceptibility to environmental changes, which could either have a genetic basis (thrifty genotype) or arise form fetal programing (thrifty phenotype). However these would make different predictions for the future. The former would predict continuing high levels of disease unless people reduce their lifestyle risk factors and become less obese. The later would predict a downturn in disease as better nutrition of girls and mother leads to improved fetal nutrition.

The 'genes $v s$ environment' debate is currently stimulating a great deal of hypothesis-testing research in this field. 
With increasing understanding of epigenetic effects and gene-environment interactions, it is no longer possible to think of disease as being either 'genetic' or environmental.

\section{Relevance of FOAD to India and Developing Countries}

The linear and graded trends in CVD mortality with birth weight suggest that majority of the world's population experience suboptimal fetal growth being highest in developing countries. In India, the mean full-term birth-weight is 2.6 to $2.7 \mathrm{~kg}$, almost $1 \mathrm{~kg}$ lower than in Western Europe. ${ }^{24}$ A high proportion of infants and children in India are still undernourished, but with economic progress, childhood and adult obesity is an emerging problem, especially in cities. It is estimated that $20 \%$ of women and $16 \%$ of men in India will be overweight $\left(\mathrm{BMI}>25 \mathrm{~kg} / \mathrm{m}^{2}\right)$ by the year $2020 .^{25}$

Furthermore, there is evidence that any level of BMI, South Asian is and women have a higher fat mass, more centrally distributed fat, and a higher risk of Obesity associated disease than white caucasians. ${ }^{26}$ According to the FOAD hypothesis, increasing child and adult obesity in combination with persistently poor fetal growth creates a high-risk for adult CVD and diabetes more, so because of undergoing rapid economic development and modernization. In India mortality from cardiovascular disease is expected to rise by about $60 \%$ and overtake deaths from infectious disease, by 2015-20. ${ }^{27}$ The prevalence of type 2 diabetes has increased by $40 \%$ in Chennai, India between 1988 and $1994 .{ }^{30}$ King has predicted ${ }^{28}$ that the prevalence of type 2 diabetes will rise by $30 \%$ world wide, from 4.0 to $5.4 \%$ by 2025 , and that the proportional rise will be greatest in developing countries (48\%), especially China (68\%) and India (59\%). India will have more people with diabetes ( 57 million) than any other country, with the greatest numbers in the 45 to 64 years age group with likelihood increase in type 2 diabetes in children. There are many research projects under way in various parts of India, i.e. Pune, Mysore, New Delhi, Vellore and some setup by ICMR to clarify the relative importance in Indian populations, of maternal size and body composition, and individuals own neonatal size, childhood growth and adult body composition and life style to CVD risk.

\section{Public Health Implications and Future Research}

The FOAD hypothesis is attractive because it suggests that several common degenerative diseases could be prevented by improving maternal health and fetal development. Data from experimental animals provide powerful evidence that a mother's nutrition programs the metabolism of her offspring. Future research (Epidemiological as well as Experimental) is in progress through out world to explore the relationships between prenatal, natal and post-natal life and also on fetal retardation, its neuroendocrine and metabolic effects; and the possible mechanism by which metabolism, body composition and growth may be permanently affected. Thus, the public health implications of this concept are quiet this evident.

\section{NUTRITIONAL INTERVENTIONS FOR PREVENTION OF ADULTHOOD DISEASES}

\section{Nine Months of Pregnancy ........Nine Challenges}

- NTDs

- Spontaneous miscarriage

- Recurrent abortion

- IUGR

- Pre-eclampsia

- Placental abruption

- Intrauterine fetal death

- Preterm labor

- Other congenital defects.

\section{AIM OF OBSTETRICAL CARE}

\section{Top Three Best Practices to Improve Birth Outcomes and reduce High-risk Births (NGA, June 2004)}

- Improve access to medical care and healthcare services

- Encourage good nutrition and healthy lifestyles

- Eating healthy foods

- Taking folic acid (methylating agents)

- Reduce use of harmful substances.

\section{Pregnancy-Importance of Nutrients (Fig. 5)}

- There are periods before and during pregnancy in which specific nutrients are required for optimal development. There is growing evidence that optimal dietary intake of important nutrients, like iodine, docosahexaenoic acid (DHA), choline, and folate, is necessary during pregnancy and lactation (Am J Clin Nutr 2009;89(suppl):685S-7S).

- Fetal nutritional status is affected by the intrauterine and childhood nutritional experiences of the mother.

- Maternal nutritional status at time of conception is an important determinant of outcomes.

- Intrauterine nutritional environment affects health and development of the fetus throughout life.

\section{Hyperhomocysteinemia as a Risk Factor}

- Women who develop severe pre-eclampsia have higher plasma homocysteine levels in early pregnancy than 


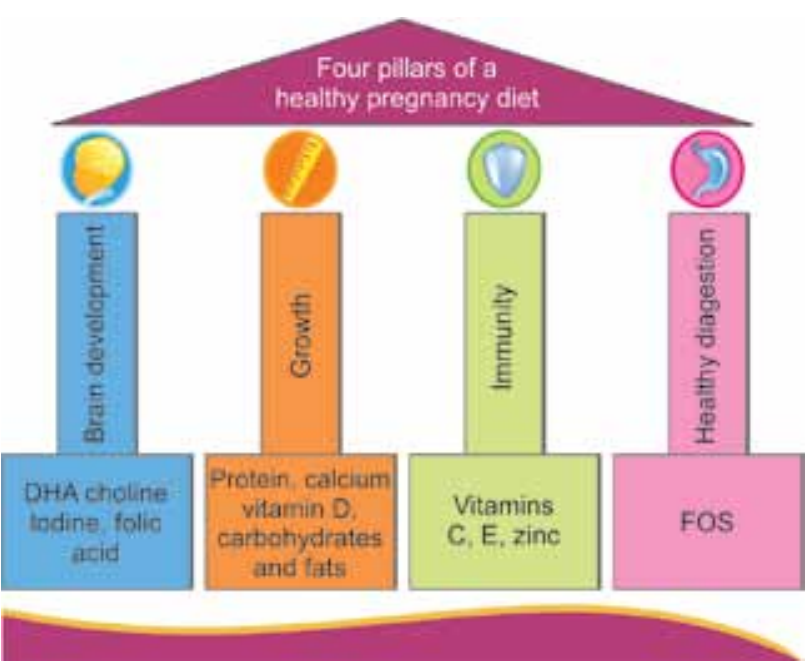

Fig. 5: Pillars of healthy pregnancy

women who remain normotensive throughout pregnancy. (threefold risk) - Cotter AM, Molloy AM, et al, Am J Obstet Gynecol 2002 May;186(5):1107; Am J Obstet Gynecol 2001 Oct;185(4):781-5.

- Pregnant women with hyperhomocysteinemia have a 7.7-fold risk for pre-eclampsia.

- Hyperhomocysteinemia is associated with pre-eclampsia as well as eclampsia, but in eclampsia the severity of homocysteine elevation is more compared to that in pre-eclampsia.

Homocysteine is regulated by:

- Genetic factors

- Nutritional factors

- Age

- Pregnancy

- Normal value -5 to $15 \mathrm{micromol} / \mathrm{lit}$

LÃ $\tilde{A}^{3}$ pez-Quesada E, Vilaseca MA, Lailla JM. Eur J • Essential

Obstet Gynecol Reprod Biol 2003 May 1;108(1):45-49.

\section{DISORDER OF METHYLATION LEADS TO THESE COMPLICATIONS}

\section{MTHFR Deficiency-Hyperhomocysteinemia}

As homocysteine is nit methylated to methionine the levels of $\mathrm{H}$ increases (Fig. 6).

\section{WHY TO TREAT AND WHAT TO TREAT WITH NUTRITIONAL INTERVENTIONS?}

Perinatal outcome in patients with a history of pre-eclampsia or fetal growth restriction and hyperhomocysteinemia who are treated appears to be favorable. Leeda M Riyazi. Am J Obstet Gynecol 1998 Jul;179(1):135-9.

\section{BRAIN NUTRITION}

\section{Docosahexaenoic Acid}

- Docosahexaenoic acid (DHA, 22: 6n23) limited capacity for synthesis inside body, hence conditionally required in diet.

- Major omega-3 fatty acid needed to build fetal brain.

- Critical period during which dietary DHA may be needed to optimize brain development extends from mid-pregnancy into the first year of life.

- DHA accumulation in fetal brain is most rapid during the last intrauterine trimester and first year of life.

- DHA is an omega-3-fatty acid and is derived from alpha-linolenic acid. It accounts for about $40 \%$ of polyunsaturated fatty acids in the brain and $60 \%$ in the retina.

\section{Omega Fatty Acids}

- Dietary source: sea food

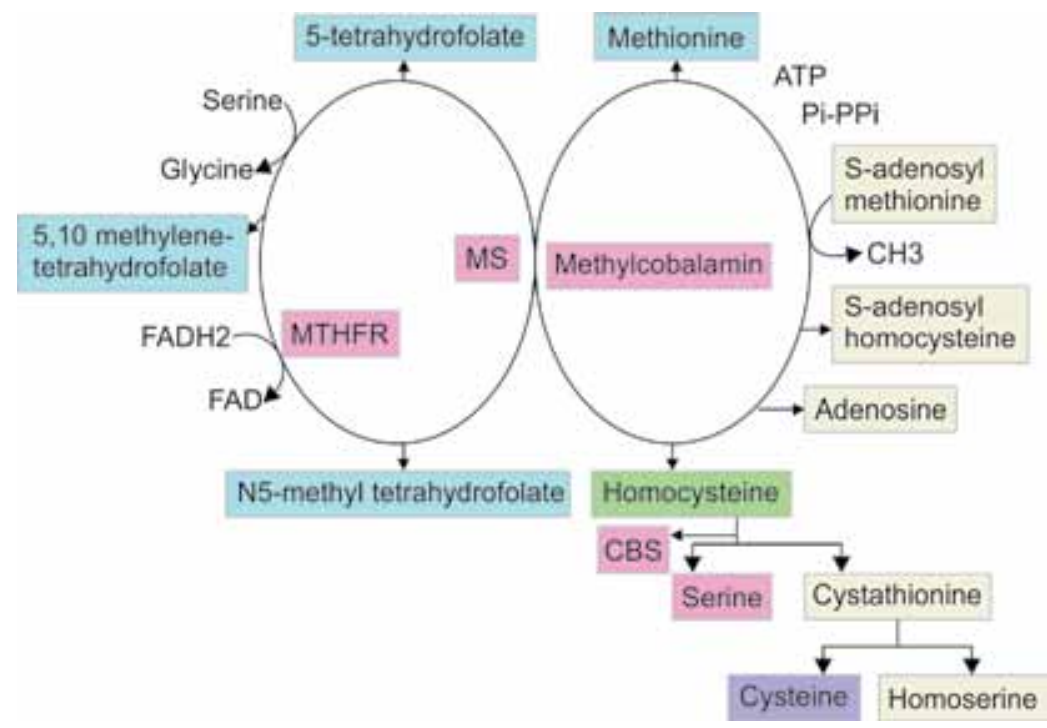

Fig. 6: Homocysteine pathway 
- India standard of 2 servings/week: Inadequate

- Critical for fetal neurodevelopment and may be important for the timing of gestation and birth weight as well

- Docosahexaenoic acid fetal development of brain and retina during 3 rd trimester and up to 18 months of life.

- EPA play role in DHA transplacental transport and intracellular absorption.

- Fatty acids of the omega-3 series (n-3 fatty acids) present in fish are well-established dietary components affecting plasma lipids and the major cardiovascular disorders, such as arrhythmias.

\section{Benefits of DHA}

Various studies have shown that a higher maternal DHA status/cord blood DHA was associated with:

- Longer gestation

- Higher visual acuity

- Better cognitive development in infants

- Studies have also shown that women with lower omega3 -fatty acids were 6 times more likely to get depressed during the antenatal period.

- A daily intake of DHA in pregnant and lactating women is recommended to be $200 \mathrm{mg}$.

\section{Folate}

- Folate deficiency has been reported in parts of India, West Africa, and Burma.

- It is due to inadequate dietary intakes, cooking habits that exacerbate losses, food taboos.

- Deficiency is associated with megaloblastic anemia, low birth weight, and potential fetal anomaly.

- Murphy et al have reported that mothers with hyperhomocysteinemia at 8 weeks of pregnancy had nearly four times the odds of giving birth to LBW neonate.

- Folate is an essential vitamin, whereas choline is class of nutrients for which there is limited capacity for synthesis inside body, and therefore conditionally required in the diet.

\section{Choline}

- Choline is required for membrane synthesis, methylation reactions, and for neurotransmitter synthesis.

- Maternal dietary deficiency of either choline or folic acid diminishes new nerve formation (neurogenesis) and increases neural cell death in the fetal brain choline status during pregnancy influences brain development in fetus.

- Transport of choline from mother to fetus depletes maternal plasma choline.

- Demand for choline is so high that stores are depleted.
- Hence supply of choline is critical during pregnancy.

- Because milk contains a great deal of choline, lactation further increases maternal demand for choline, resulting in further depletion of tissue stores.

- During pregnancy and lactation-maternal reserves depleted.

- At the same time, the availability of choline for normal development of brain is critical.

- Lack of choline in a mother's diet during pregnancy and lactation may have life-long adverse effects on their child.

- The Institute of Medicine (IOM) of the National Academy of Sciences set an adequate intake (AI) level for choline of $550 \mathrm{mg}$ /day for men and $425 \mathrm{mg}$ /day for women.

\section{Folic Acid (Fig. 7)}

Important cofactor in the Remethylation of Homocysteine

- Neural tube defects (NTDs) are common (the most common malformations of the central nervous system and probably second only to cardiac defects) among major congenital anomalies.

- Maternal folic acid supplementation prevents a substantial proportion of NTDs.

- American College of Obstetricians and Gynecologists and American Academy of Pediatrics, Food and Nutrition Board of the Institute of Medicine also recommended that all women capable of becoming pregnant should consume $0.4 \mathrm{mg}$ of folate daily from supplements or fortified foods or a combination of the 2 in addition to consuming folate from a varied diet.

- Adequate intake minimizes DNA uracil and plasma homocysteine accumulation, resulting in reduced risk of chromosome breaks.

- Folic acid-vitamin B supplementation plays important role in nucleic acid synthesis.

- Marginal folate intake during gestation can impair cellular growth and replication in the fetus or placenta.

- Sustained intake after complete closure of the neural tube to decrease the risk of other poor pregnancy outcomes.

- During pregnancy, low concentrations of dietary and circulating folate are associated with increased risks

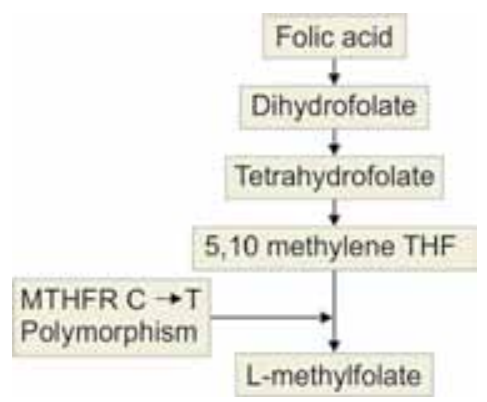

Fig. 7: Pathway of folic acid 
of preterm delivery, infant low birth weight, and fetal growth retardation.

- Significantly reduce tHcy levels (Bostom et al, 2002).

- Low conc associated with risk of preterm delivery, low birth weight infants and FGR

AJCN 2000;71:1295S-1303S,

Am J Obstet Gynecol 2004 Dec;191(6):1851-7.

- L-methylfolate is the primary biologically active form of folate ${ }^{1}$ and the primary form of folate in circulation.

- Folic acid, the synthetic form of folate, must undergo enzymatic reduction by methylenetetrahydrofolate reductase (MTHFR) to become biologically active

- In Females:

- Folic acid plays important role in oocyte quality and maturation, implantation, fetal growth and organ development.

- In Male:

- Folic acid plays an important role in DNA synthesis and in spermatogenesis.

- Folic acid proves to increase sperm count, enhance sperm motility and reduces immature cells in semen.

- L-methylfolate is a substantially pure source of L-methylfolate containing not more than $1 \% \mathrm{D}$-methylfolate.

- D-methylfolate is not metabolized by the body and inhibits regulatory enzymes related to folate and homocysteine metabolism and reduces the bioavailability of L-methylfolate.

\section{Vitamin $B_{12}$}

A cofactor, methionine synthetase (MS) in methylation

- Enzyme, catalyses the transfer of $\mathrm{CH}_{3}$ group from

- Methyltetrahydrofolate

- Homocysteine.

- In vitamin $\mathrm{B}_{12}$ deficiency, folate is trapped as unusable MTHF, causing functional folate deficiency.

- Thus plays a key role in the remethylation of homocysteine to methionine.

\section{Vitamin $\mathrm{B}_{6}$}

- Reduces the level of homocysteine by the process of trans-sulfuration to cysteine and hence related pregnancy complications are reduced.

- Vitamin $\mathrm{B}_{6}$ levels of mothers at the onset of pregnancy have a positive correlation with birth weight of newborns [Int J Vitam Nutr Res 1978;48(4):341-7].

Needed for CNS formation of fetus.

\section{lodine}

- Providing adequate iodine in mid-to-late pregnancy improves infant cognitive development, there are greater benefits when iodine is given before or early in pregnancy.
- WHO increased their recommended iodine intake during pregnancy from 200 to $250 \mu \mathrm{g} / \mathrm{d}$ and suggested a median urinary iodine (UI) concentration of 150 to $249 \mathrm{lg} / 1$ indicates adequate iodine intake in pregnant women.

- Cross-sectional studies reported impaired intellectual function and motor skills in children from iodinedeficient areas.

- An adequate iodine supply should continue after child birth.

- Iodine requirement of women who is fully breastfeeding her infant is even higher than that during pregnancy.

- Iodine deficiency is a preventable cause of mental impairment.

- Supplementation may be effective at preconception up to mid-pregnancy period.

- Form of iodine supplementation (iodinating food or oral/ injectable iodine) depend on:

- Severity of iodine deficiency

- Cost

- Availability of different preparation.

\section{GROWTH NUTRIENTS}

\section{Calcium}

- Developing fetal skeleton accumulates about $30 \mathrm{gm}$ of calcium by term, about $80 \%$ of it during the third trimester.

- Women lose 300 to $400 \mathrm{mg}$ of calcium daily through breast milk, this calcium demand is met by a 5 to $10 \%$ loss of skeletal mineral content during 6 months of exclusive lactation.

- Women nursing twins, $\mathrm{Ca}$ losses may be as great as 1000 mg or more.

- Limited maternal intake of $\mathrm{Ca}$ and other minerals may adversely affect fetal skeletal development, or perhaps lead to severe losses of maternal bone mineral content during pregnancy.

- Low calcium intake might adversely affect fetal development, and is important to recommend calcium supplementation during pregnancy.

- Recommend increase in calcium intake through diet in women at risk of hypertension or low calcium areas.

- Reduction of incidence of PIH.

- Calcium decreases risk pre-eclampsia, low birth weight, and chronic hypertension in children.

- Maintain bone strength.

\section{Vitamin D}

- Maternal vitamin D deficiency during pregnancy was reported about $18 \%$ in UK, $25 \%$ in the UAE, $80 \%$ in Iran, $42 \%$ in northern India, $61 \%$ in New Zealand and 60 to 
$84 \%$ of pregnant non-Western women in the Netherlands, have been shown serum concentrations of $25(\mathrm{OH}) \mathrm{D}(25$ Hydroxy vitamin D3) $<25 \mathrm{nmol} / \mathrm{l}$.

- Studies show that infants are entering the world with a vitamin $\mathrm{D}$ deficit that begins in utero (within womb of mother).

- Concern is based on the strong relationship between maternal and fetal (cord blood) circulating 25(OH)D levels, studies from many countries, have demonstrated a high prevalence of vitamin D deficiency in mother-infant pairs at birth.

- Significance of maternal deficiency during pregnancy fetus developing in a state of hypovitaminosis D, which likely has significant effects on fetal and childhood bone development risk of osteoporotic fracture in adulthood could be determined partly by environmental factors during fetal life and early infancy.

- In a longitudinal study, 198 children born were followed up for 9 years of age.

- Body builds, nutrition, and vitamin D status of mothers recorded during pregnancy.

- Children were followed up at age 9 years to relate these maternal characteristics to their body size and bone mass.

- Reduced concentration of $25(\mathrm{OH})$ - vitamin D in mothers during late pregnancy was associated with reduced whole-body and lumbar-spine bone-mineral content in children at age 9 years.

- Reduced concentration of umbilical-venous calcium also predicted reduced childhood bone mass.

- Vitamin D supplementation of pregnant women, could lead to reductions in the risk of osteoporotic fracture in their offspring.

\section{IMMUNE NUTRIENTS}

\section{Antioxidants}

- Selenium-A trace element which has antioxidant and anticancer properties

- Vitamin E-A powerful antioxidant-protects against damaging effect of free radicals

- Combats oxidative stress, which is an important factor in IUGR, NTD, Placental Abruption

- Vitamin C-Antioxidant and has a role in immune system

- Selenium-A trace element which has antioxidant and anticancer properties

- Vitamin E-A powerful antioxidant_-protects against damaging effect of free radicals

- Combats oxidative stress - which is an important factor in IUGR, NTD

- Zinc is an essential trace element for all forms of life

- Numerous aspects of cellular metabolism are zincdependent
- Zinc plays important roles in growth and development, the immune response, neurological function, and reproduction

- $\mathrm{RDA}-12$ to $15 \mathrm{mg} / \mathrm{d}$

- In female:

- Enhances maternal and fetal immunity

- Improves the fertility outcome

- Promotes bone growth and metabolism

- Shows positive impact on maternal and fetal immunity

- In male:

- Zinc helps in elevating sperm count

- In women at high-risk of having lower birth weight infants, supplementation with $25 \mathrm{mg} \mathrm{Zn} /$ day, beginning at an average of 19 weeks gestation was evaluated

- There was greater fetal growth (including head circumference) that was independent of gestational age

- Goldberg RL JAMA 1995;274:463-468

- Prophylactic doses of 20 to $25 \mathrm{mg}$ of elemental zinc/ day have been used in developing countries with WHO setting the upper limit at $35 \mathrm{mg}$ /day

- Vitamin E is nature's most effective lipid-soluble, chain-breaking antioxidant, protecting cell membranes from peroxidative damage

- Research evidence suggests that an adequate intake of vitamin $\mathrm{E}$ and the other antioxidants can provide protection from the increasingly high free-radical concentrations caused by air pollutants and current lifestyle patterns.

\section{L-arginine (Fig. 8)}

L-arginine is an amino acid involved in-

- Vascular regulation

- Immune activity

- Endocrine function

- Protein production

- Wound healing

- Erectile function

- Fertility

- Reverse IUGR

- L-arginine $3 \mathrm{gm} /$ day orally accelerated fetal growth with mean value of $2526 \mathrm{gm}$

- Neonates delivered in L-arginine group revealed higher Apgar score, better umbilical cord acid-base status

- Lower incidence of RDS and admission to NICU

- L-arginine orally in dose $6 \mathrm{gm} /$ day in gestation complicated by pregnancy induced hypertension

- They found a normalization of blood pressure

- Increased nitrite/nitrate levels that usually are decreased in pre-eclamptic patients. 


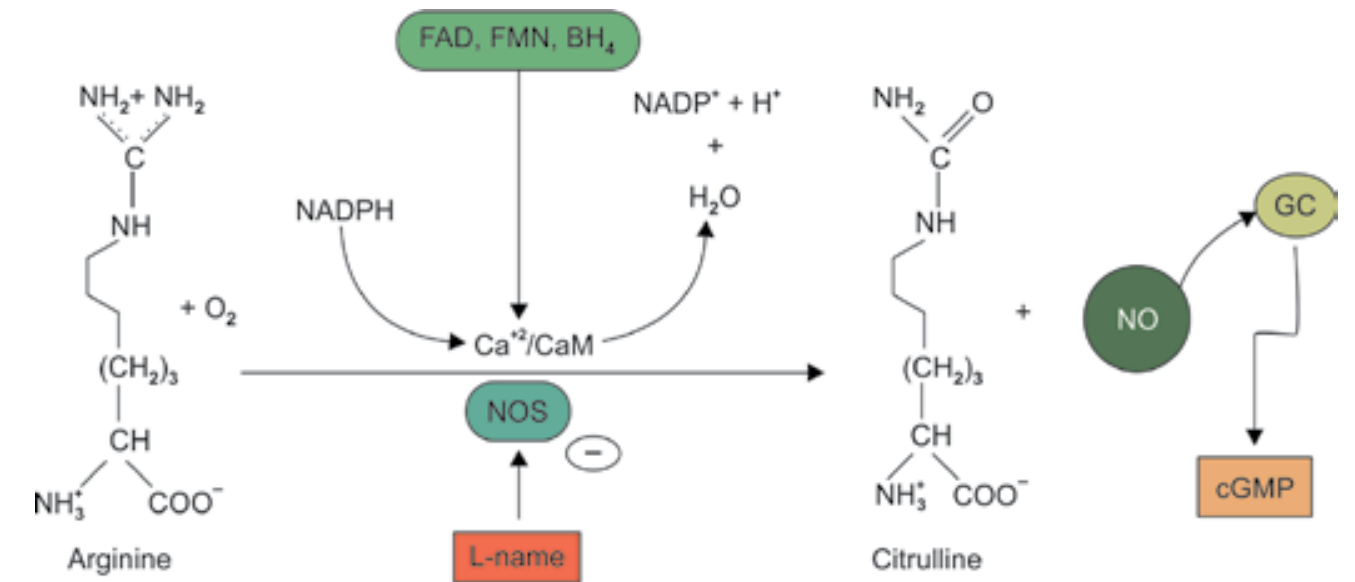

Fig. 8: L-arginine is the precursor for nitric oxide (NO); NO improves uteroplacental blood circulation and increase oxygen delivery to fetus

- Second trimester amniotic fluid levels of NO in women who subsequently developed IUGR have been shown to be lower than in controls.

- NO could play an important role in the prevention and treatment of IUGR as it can improve uteroplacental circulation increasing fetal blood supply.

- Pre-eclampsia is associated with decreased endothelial nitric oxide synthase expression, which increases cell permeability (Wang, 2004).

- Nitric oxide maintains the normal low-pressure vasodilated state characteristic of fetoplacental perfusion (Myatt, 1992).

\section{DIGESTIVE NUTRIENTS}

\section{Fructo-oligo Saccharides (FOS)}

- Stimulate the growth of beneficial bacteria present in colon

- Growth of beneficial bacteria helps in keeping healthy and strong large intestine

- Prebiotics keep

- Beneficial bacteria healthy

- Have lipid reducing activity

- Boost the immune system

- Help in improving mineral absorption and balance

- Clear the gut of harmful microorganisms

- Help in prevention of constipation and diarrhea human gut microflora can play a major role in host health

- Prebiotics are nondigestible food ingredients that beneficially affect the host by selectively stimulating the growth and/or activity of one or a limited number of beneficial bacterial species already resident in the colon, and thus help to improve host health

- Intake of prebiotics can significantly modulate the colonic microflora by increasing the number of beneficial bacteria and thus changing the composition of the microflora.

\section{Dietary Fiber}

Dietary fiber preparation from defatted rice bran has laxative and cholesterol-lowering ability with attendant benefits toward prevention or alleviation of cardiovascular disease, diabetes, diverticulosis and colon cancer.

\section{CONCLUSION}

It will be possible to ascertain the genetic predisposition to disease of a given individual or population and then implement behavioral and/or pharmacological interventions to delay or prevent disease or to improve treatment.

Fetal origins of adult disease deserves deeper and further studies, and their results must be strongly voiced and openly discussed because of their very important varied implications.

- 'Nutraceutical' is a made-up word combining the words nutrition and pharmaceuticals, creating the concept that extracts from food can be used as drugs, i.e. food supplements (Fig. 9)

- Nutraceuticals (often referred to as phytochemicals or functional foods) are natural, bioactive chemical

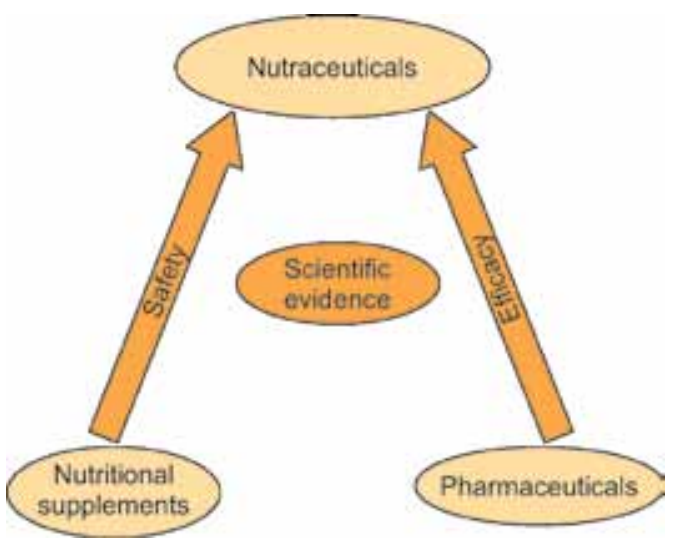

Fig. 9: Nutraceuticals combine the word nutrition and pharmaceuticals 
compounds that have health promoting, disease preventing or medicinal properties

- There is a lot of confusion regarding the terminologies like-Nutraceuticals

- Functional foods

- Dietary supplements

- Designer foods

- Medical foods

- Pharmafoods

- Phytochemicals, etc.

- Nutraceuticals are present in most of the food ingredients with varying concentration

- Concentration, time and duration of supply of nutraceuticals influence human health

- Manipulating the foods, the concentration of active ingredients can be increased

- Diet rich in nutraceuticals along with regular exercise, stress reduction and maintenance of healthy body weight will maximise health and reduce disease risk.

'The doctor of the future will give no medicine, but will interest his patient in the care of the human frame, in diet and in the cause and prevention of disease'

-Thomas Edison

\section{REFERENCES}

1. Barker DJP. Mothers, Babies and Health in Later Life. 2nd ed. London, Churchill Livingstone, 1998.

2. Forsdahl A. Are poor living conditions in childhood and adolescence an important risk factor for arteriosclerotic heart disease? Br J Prev Soc Med 1977;31:91-95.

3. Barker DJP. The fetal origins of adult disease. Fetal and Maternal Medicine Review 1994;671-680.

4. Waterland RA, Garza C. Potential mechanisms of metabolic imprinting that lead to chronic disease. Am J Clin Nutr 1999; 69:179-197.

5. Phillips DIW. Insulin resistance as a programmed response to fetal undernutrition. Diabetologia 1996;39:1119-1122.

6. Fall CHD, Yajnik CS, Rao S, Coyaji KJ, Shier RP. The effects of maternal body composition before birth on fetal growth: the Pune Maternal Nutrition and Fetal Growth Study. In: Fetal Programming; Influences on Development and Diseases in Later Life. O'Brien PMS, Wheeler T, Barker DJP, editors. RCOG Press, London, 1999.

7. Barker DJP, Osmond C, Winter PDW, Margetts B, Simmonds SJ. Weight in infancy and death from ischemic heart disease. Lancet 1989;2:577-580.

8. Barker DJP, Osmond C, Simmonds SJ, Wield GA. The relation of small head circumference and thinness at birth to death from cardiovascular disease in adult life. BM 1993;306:422-426.

9. Martyn CN, Barker DJP, Osmond C. Mother's pelvic size, fetal growth, and death from stroke and coronary heart disease in men in the UK. Lancet 1996;348:1264-1268.

10. Frankel S, Elwood P, Sweernam P, Yarnell J, Davey Smith G. Birth weight, body mass index and incident coronary heart disease. Lancet 1996;348:1478-1480.
11. Lithell HO, McKeigue PM, Berglund L, Mohsen R, Lithell U, Leon DA. Relation of size at birth to non-insulin dependent diabetes and insulin concentrations in men aged 50-60 years. BMJ 1996;312:406-410.

12. Yarborough DE, Barrett-Connor E, Kritz- Silverstein D, Ingard DL. Birth weight, adult weight, and birth as predictors of the Metabolic Syndrome in postmenopausal women. Diabetes Care 1998;21:1652-1658.

13 Goodfellow J, Bellamy MF, Gorman ST, Bownlee M, Ramsey MW, Lewis MJ, et al. Endothelial function is impaired in fit young adults of low birth weight. Cardiovas Res 1998;40: 600-606.

14. Weyer C, Pratley RE, Lindsay RS, Tataranni A. Relationship between birth weight and body composition, energy metabolism and sympathetic nervous system activity later in life. Obes Res 2000;8:559-565.

15 Gale CR, Martyn CN, Kellingray S, Eastell R, Cooper C. Intrauterine programming of adult body composition. J Clin Endocrinol Metab 2001;86:267-272.

16 Law CM, Barker DJP, Osmond C, Fall CHD, Simmonds SJ. Early growth and abdominal fatness in adult life. J Epidemiol Com Hlth 1992;46:184-186.

17. Barker M, Robinson S, Osmond C, Barker DJP. Birth weight and body fat distribution in adolescent girls. Arch Dis Child 1997; 77:381-383.

18. Barker DJP, Meade TW, Fall CHD, Lee A, Osmond C, Phipps $\mathrm{K}$, Stirling Y. Relation of fetal and infant growth to plasma fibrinogen and factor VII concentrations in adult life. BMJ 1992; 304:148-152.

19. Fall CHD, Barker DJP, Osmond C, Winter PD, Clark PMS, Hales CN. Relation of infant feeding to adult serum cholesterol concentration and death from ischemic heart disease. BMJ 1992; 304:801-805.

20. Phillips DIW. Insulin resistance as a programmed response to fetal undernutrition. Diabetologia 1996;39:1119-1122.

21. Huxley R, Neil A, Collins R. Unravelling the fetal origins hypothesis: is there really inverse association between birthweight and subsequent blood pressure? Lancet 2002;360: 659-665.

22. niehs, nih.gov/oc/factsheets/ceh/birth.htm.

23. Morton NE. The inheritance of human birth-weight. Ann Hum Genet 1955;20:125-134.

24. Asia Development Bank and International Food Policy Research Institute. Malnutrition in Asia and the Pacific in Attacking the Double Burden of Malnutrition in Asia and the Pacific. Gillespie S, Haddad L, editors. Asian Development Bank, Manila, Philippines, and International Food Policy Research Institute, Washington, USA. ADS Nutrition and Development Series No. 4;2001.

25. Reddy KS. Cardiovascular disease in developing countries: dimensions, determinants, dynamics and directions for public health action. Pub Hlth Nut 2002;5:231-237.

26. Ramachandran A, Snehalatha C, Latha E, Vijay V, Viswanathan M. Rising prevalence of NIDDM in an urban population in India. Diabetologia 1997;40:232-237.

27. Reddy KS. Cardiovascular disease in developing countires: dimensions, determinants, dynamics and directions for public health action. Pub Hlth Nut 2002;5:231-237.

28. King H, Aubert RE, Herman WH. Global burden of diabetes, 1995-2025; prevalence, numerical estimates and projections. Diabetes Care 1998;12:1414-1431. 